Vol. 9(14), pp. 309-319, 30 July, 2014

DOI: $10.5897 /$ IJPS2014.4152

ISSN 1992 - 1950

Article Number: D031B4646338

Copyright (C) 2014

Author(s) retain the copyright of this article

http://www.academicjournals.org/IJPS

International Journal of Physical Sciences

\title{
Optimal transformer allocation in electrical distribution using genetic algorithm
}

\author{
Oluwole Charles Akinyokun, Gabriel Babatunde Iwasokun* and Akinwale Michael Ojo \\ Department of Computer Science, Federal University of Technology, Akure, Ondo State, Nigeria.
}

Received 4 April, 2014; Accepted 30 June, 2014

\begin{abstract}
The optimization of transformers allocation is a major challenge to the operators of electrical energy distribution in several developing countries. In this research, a Generic Algorithm model for the optimization of transformer allocation in electrical distribution networks is developed. The algorithm employed the principles of selection, crossover and mutation to allocate transformers of different capacities to various substations in order to achieve their optimum performance. The objective function was subjected to cost and power capacity of each transformer as well as the growth rate and power consumption of the region. The initial population of chromosomes was generated at random with each consisting of potential solution to the problem. The chromosomes were decrypted and used to estimate the objective function. The GA operations were carried out on the chromosomes to know the ones that are best fit for consideration in the next generation. Results of a case study of transformer allocation in Osogbo District of Power Holding Company of Nigeria exhibited best-fit strategies for massive exchange (redistribution) of transformers in the district.
\end{abstract}

Key words: Genetic algorithm, transformer allocation, power distribution network, optimization and power generator.

\section{INTRODUCTION}

Electricity is one of the major driving forces behind modern machines and it is the backbone of a progressive economy. A nation with erratic supply of electricity will definitely be a nation with unstable economic growth. In modern times, the supply of electricity is manned by major electricity companies and passes through the stages of generation, transmission, distribution and consumption. Most electricity is generated using coal, oil, natural gas, nuclear energy, or hydropower. Some production is done with alternative fuels like geothermal energy, wind power, biomass, solar energy or fuel cells (Milbrandt and Mann, 2009). Majority of the electricity is produced at power plants with the use of steam turbines where mechanical energy is changed into electrical energy by using various energy sources such as coal, natural gas and oil. These fuels heat water in a boiler to produce steam. The steam under tremendous pressure is used to turn a series of blades mounted on a shaft turbine. The force of the steam rotates a shaft that is connected to a generator. The spinning turbine shafts turn electromagnets that are surrounded by heavy coils of copper wire inside generators. This creates a magnetic field which causes the electrons in the copper wire to move from atom to atom creating electricity (Culverco, 2005).

*Corresponding author. E-mail: maxtunde@yahoo.com

Author(s) agree that this article remain permanently open access under the terms of the Creative Commons Attribution License 4.0 International License 
Utility companies anticipate demand for electricity and transmit it at very high voltage along system of power lines to consumers through transformers where the high voltage is "step up" or "step down". The power lines can be high as 765,000 volts which travel many hundreds of miles in a transmission grid (BOPL, 2012). Electric power distribution reliability is a measurement of how well the system provides customer adequate and secured supply of power to meet daily requirements. The concept of adequacy is generally considered to be the existence of sufficient facilities within the system to satisfy customers' demand. Several methods in which Generic Algorithm (GA) formed the bedrock have been proposed for sufficient and constant transmission of electricity to consumers through suitable and appropriate allocation of transformers. GA is a programming technique that mimics biological evolution as a problem-solving strategy. They are based on a biological metaphor, which view learning as a competition among a population of evolving candidate problem solutions (Luger, 2002; Adam, 2004). This paper presents a suitable case study, a GA-based optimization procedure for transformers allocation as one of the key elements in electrical distribution networks.

\section{Related works}

The theoretical foundations for GA were presented in (Holland, 1975; Kumara et al., 2009; Melanie, 1999) as a global search technique for solving optimization problems which is basically focused on the theory of natural selection, the process that drives biological evolution. Genetic algorithms consist of a population of binary string and searching many peaks in parallel (Bhasker et al., 2013; Li, 2009). The authors in (Mahela and Ola, 2013) studied the possibility of reducing the value of real power losses for global system transmission lines by choosing the best location to install shunt capacitors. GA is used to calculate the optimal allocation and sizing considering the value of real power losses with injection of reactive power as an indicator of the ability of reducing losses at load buses. In Carpinelli et al. (2010) optimal sizing and allocation of dispersed generation, distributed storage systems and capacitor banks are presented. The optimization focused on minimizing the sum of the costs sustained by the distributor for the power losses, network upgrading, reactive power service and the storage and capacitor installation over the planning period. A hybrid procedure based on a GA and a sequential quadratic programming-based algorithm was implemented on an 18-busbar MV balanced 3-phase network and the results confirmed its feasibility.

A heuristic backtracking search algorithm is proposed in Chia-Hung et al. (2007) for adjusting the phasing arrangement of primary feeders and laterals for phase balancing of distribution systems. The phase unbalance index of distribution feeders is calculated based on the phasing current magnitude of each line segment and branch which has been solved by a 3-phaseload flow program. Bogdan et al. (2013) proposed a method for achieving optimization through the reconfiguration of distribution systems taking into account various criteria in a flexible and robust approach.

A method for finding the optimal values of the fixed and switched capacitors in the distribution networks based on the Real Coded GA (RCGA) is presented in (RahmatAllah and Mohammad, 2007). The modeling of the loads at different levels is simulated with low and medium voltage capacitors. With various parameters in the optimization problem, RCGA is used to find the real optimal network with the best rate for the capacitors. A determination method of optimal allocation and transfer of Step Voltage Regulators (SVRs) in distribution feeders with Renewable Energy Sources (RES) is presented in (Takahashi et al., 2012). The proposed method determines the optimal allocation and transfer of SVRs based on the forecasted amount of Photovoltaic (PV) system. In the proposed method, voltage margin is maximized under a constraint that all the node voltages are controlled within the proper range for a certain period of years.

Sreejaya and lyer (2012) presents a GA based reactive power optimization for voltage profile improvement and real power loss minimization in AC-DC system. The reactive power control devices such as generators, tap positions of on-load tap changer of transformers, shunt capacitors, converter transformer tap positions and firing angles (Al-Abdulwahab, 2007; Ellithy et al., 2008) were used to correct voltage limits violations while simultaneously reducing the system power losses. Shahram (2006) proposed a system for evaluating the optimum allocation of any power system elements such as power plant, substation and capacitors. The system operates on GA and uses heuristic rules for its operations. The system finds substation allocation in optimum point with regard to its place and size. The mathematical model of the problem uses minimum investment costs and power loss to obtain the goal. Tiago et al. (2011) made a comparison between GA and particle swarm optimization (PSO) as tools for providing solution to switch allocation problem. The two algorithms used fuzzy expert system (FES) for making engineering judgment in the solution of the switch allocation problem. The models and techniques proposed were validated and applied in a large scale substation with the results showing the performance level of the two algorithms. The authors in Lijun et al. (2008) present optimal choice and allocation of devices in multi-machine power systems using GA. Focus was on achieving the power system economic generation allocation and dispatch in deregulated electricity market.

\section{PROPOSED GA MODEL FOR OPTIMAL TRANSFORMER ALLOCATION}

The first phase of the algorithm is concerned with the survey of 
some baseline data of transformer in each substation. The baseline data include power rating of transformer, estimated power consumption in the service area that is being serviced by the transformer, age of the transformer, classification of consumer (residential/commercial/industrial) and estimated percentage load growth of the area.

The second phase is concerned with developing a model of genetic algorithm procedure with a view of placing transformers in a substation for maximum capacity utilization. The model is characterized by a database of substation. The system employs a mono-objective optimization technique which is aimed at maximizing the capacity utilization of a transformer relative to its position in the electrical distribution network. The technique has a mechanism for guiding against over-utilization which can lead to quick ageing or breakdown of the transformer. Moreover, it involves the re-allocation of the existing transformers in the distribution network and resizing of an existing network by providing the capability of adding new nodes.

The third phase is concerned with the repositioning of transformers for better performance such that, the transformers that have less power to supply their substation are replaced. The design is presented under the transformer allocation in electrical distribution networks and data entry, genetic algorithm processing and result presentation design.

A typical substation comprises a distribution transformer, an incoming high voltage line, switches, circuit breakers, and other equipment needed to deliver electric power to the customer at the required voltages (U.S. Department of Labor, 2009). The factors that affect and determine the performance of transformers in an electrical distribution network include weather (storms, snow, temperature and humidity), contamination and humidity, excessive ambient temperature, excessive load and ageing. The design of transformer allocation in electrical distribution networks is driven by power flow analysis, load growth analysis and ageing factor.

\section{Genetic representation of transformers in distribution network}

The basis of genetics in nature is a chromosome. In the search space, each solution to the problem at hand, need to be encoded so that it can be thought of as a chromosome. Originally, genetic algorithm was designed with the idea of using binary string as a means of encoding (Mitchell, 1999). However, in a problem such as this, encoding binary string is not a natural way for representing the problem instead, what is designed is an encoding based upon the ordinary value where the position of each value represents where the transformer should be transferred to. In transformer allocation, the transformers are represented by 3-digits, while the position of the 3-digit gene in the chromosome represents the substation where the transformer is to be taken to. Each chromosome in the population is associated with a fitness value that is calculated using the fitness function. The fitness value indicates the satisfactory level of the solution being offered by the chromosome (Mitchel, 1999). This information is used to select the chromosomes that will contribute to the formation of the next generation of solution.

Crossover basically means that first part of the chromosome is exchanged with a part of the second chromosome, while the other parts of the chromosomes are equally exchanged. In a nutshell, crossover involved the genes of two chromosomes to be exchanged in an orderly manner. The individual chromosomes randomly organized pair wise, have their space location consumed in such a way that each former pair of individuals give rise to a new pair. The prompt to be used for Crossover is chosen randomly, different result is achieved by positioning the crossover point randomly.

Some individuals in the chromosome are randomly modified, that is, one (1) will change to 0 and 0 will change to one (1). Mutation is required after crossover because it prevents the solution from converging towards local optimal. Mutation involves selecting a gene represented by 3 -digits in the chromosome and randomly altering one of the 3 digits.

\section{Design of optimal allocation of transformers}

Genetic algorithms are mainly used for optimization techniques (either to minimize or maximize). The model here is to maximize the capacity utilization of each transformer in the distribution system subject to the various parameters attached to each substation. The framework for the design in the system is provided in Figure 1 and has data entry, optimization procedure and result presentation.

The data to be entered into the system will basically serve as input to the genetic algorithm processing procedure. The kind of data required are not the type that is processed in peace-meal, but is bounded for processing as a whole. The required data for the system are divided into the following:

a. Genetic algorithm control parameters: The value of the control parameters influences the performance of the genetic algorithm processing module (Ellithy, 2007). It is used to alter the behavioral pattern of how the algorithm operates. For example, generations required by the optimization depends on the value of the control parameters. The control parameters that will be entered into the system include population size, crossover type, mutation probability, number of years for the model and number of iterations. b. Substation records: Depending on the number of substations to be considered in the optimization system, the following parameters are used to test the objective function for optimizing the transformer in each substation:

i. Power rating of the transformer,

ii. Estimated power consumption of the area,

iii. Age (years) of the transformer,

iv. Consumer classification (Residential or Industrial),

v. Growth rate of the area.

The data are obtained and sent to the genetic algorithm procedure for processing and storage into a database for future retrieval and reprocessing. The database is as follows:

a. District \{district name, state of origin, substation, population size, mutation probability, crossover type, number years of model, number of iteration\},

b. Substation \{substation id, transformer id, transformer power rating, transformer type, age of transformer, power consumption in the area, consumer classification\},

c. Optimized transformer \{substation id, initial substation id, transformer id, transformer power rating, transformer type, power consumption in the area, consumer classification\}.

The data entry system represents an interface between the genetic algorithm processing and the stored substation records. At the data entry system, users request is transformed into a structured query language (SQL). The system dynamically fetches all the substation records regarding the district and is sent to the genetic algorithm processing unit.

Objective function: Based on the factors that affect the performance of a transformer in a distribution network, the monoobjective task of this genetic algorithm is based on the maximization of capacity utilization of individual transformers in the distribution networks considering the following parameters relating to a substation:

a. Power rating of the transformer,

b. Power consumption of the area (load demand), 


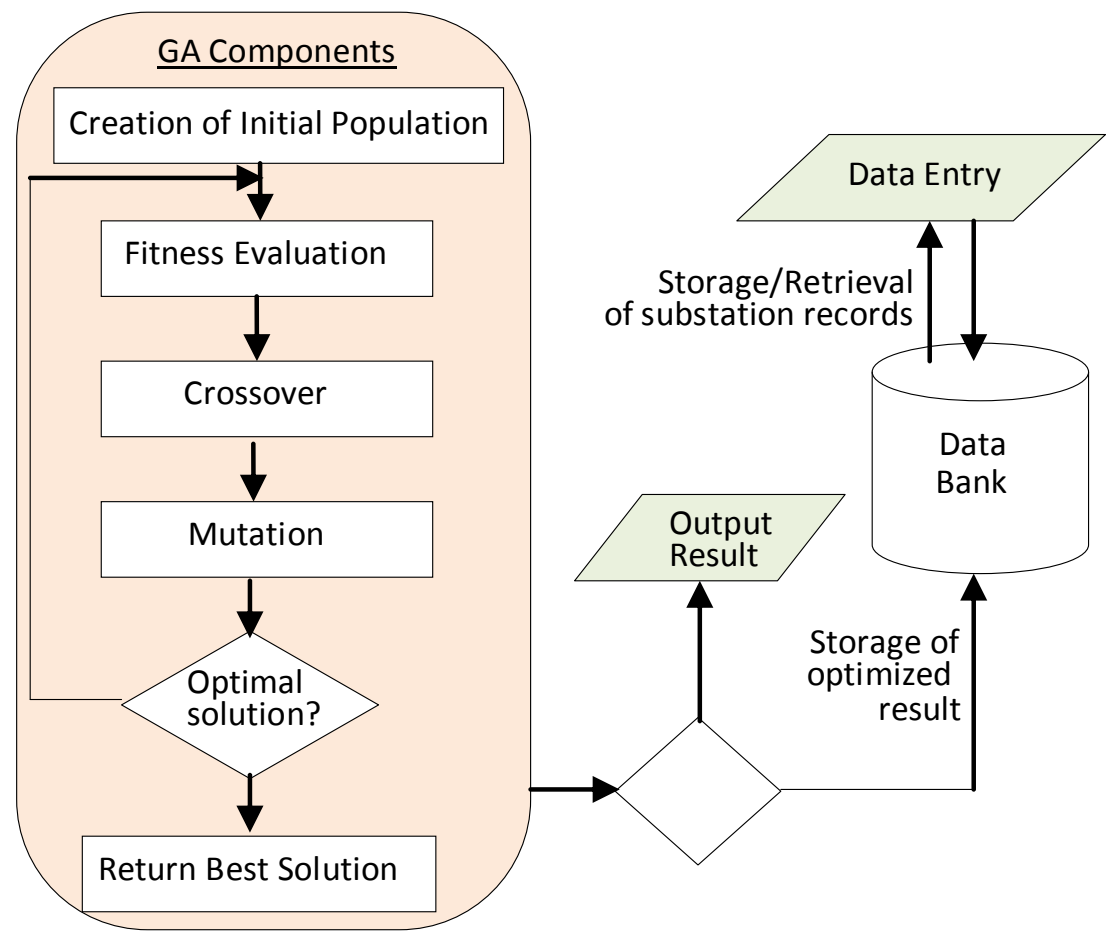

Figure 1. The design architecture.

c. Appreciation of power demand of the area for the specified period of time (load growth),

d. Ageing factor of the transformer,

e. Marginal fluctuation in power demand in the area.

The objective function, $\mathbf{Z}$ for the optimal transformer allocation in electrical distribution networks is given as:

$$
\operatorname{Max} Z=(T[i]-A[i])-(P[i]+L[i]+M)
$$

Subject to the decision variables: $T[i]=$ power rating of the transformer at the substation, $A[i]$ represents ageing factor of the transformer, $P[i]=$ the power consumption at the substation, $L[i]$ = the annual load growth of the area, and $M=$ electricity marginal variation in demand.

\section{Optimization procedure}

Genetic algorithms use a "chromosomal" representation which requires the solution to be coded as a finite length of string (Ellithy, 2007). The procedure for optimizing the allocation of transformers in electrical distribution networks is based on the following processes:

a. String representation: In genetic algorithm, a chromosome represents a potential solution in a way to the domain problem. In the context of transformer allocation, a chromosome is a string of bits (comprising of 0 's and 1's) which when decoded, represent a complete arrangement of the transformers in the distribution network. In the context of genetic algorithm for optimizing the allocation of transformers in electrical distribution networks, a gene is a group of 3 digits, which when decoded, represent the substation number (position) in which the transformer is to be placed in the distribution system. The substations in the distribution network are numbered from $1,2,3, \ldots, \mathrm{N}$, where $\mathrm{N}$ is the number of substations.

Hence, a chromosome comprises of bits that are three times the number of substations in the distribution network. Each 3 group of digits which is a gene is decoded to represent the substation position of the transformer in the distribution network. For example, supposing $\mathrm{T} 1, \mathrm{~T} 2, \mathrm{~T} 3, \ldots \mathrm{T}_{\mathrm{N}}$ are transformers in substations $\mathrm{S} 1, \mathrm{~S} 2$, S3, ..., $S_{N}$ respectively, a chromosome defined as: 020017 $005 \ldots . .128$ will give the arrangement as in Table 1.

This means that Transformer T1 is allocated to substation 20, Transformer T2 is allocation to substation 17, transformer T3 is allocated to substation 5 and transformer $T_{N}$ is allocated to substation 128.

b. Initial population generation: The population refers to the number of chromosomes which will undergo evolutionary procedure to eventually produce a single chromosome that will be picked as the optimal value. The illustration above represents just one chromosome. For instance, if the population size selected for the algorithm is 700, then this number of chromosomes will be generated at random. Initially, they may hold no promise, but after they have undergone the evolutionary procedure of genetic algorithm, they will eventually produce a single chromosome that 'best-fit' the arrangement of transformers in the distribution network. c. Fitness evaluation: The gene (location) for each transformer is tested in their environment (substation) using the various parameters relating to that substation such as:

i. Power rating of the transformer,

ii. Power consumption of the area (load demand),

iii. Power load growth of the area for the specified period of time, iv. Ageing factor of the transformer, 
Table 1. Chromosome arrangement of the transformers.

\begin{tabular}{ccccc}
\hline T1 & T2 & T3 & $\ldots \ldots \ldots \ldots \ldots$ & $T_{N}$ \\
\hline 020 & 017 & 005 & $\ldots \ldots \ldots \ldots \ldots$ & 128 \\
\hline
\end{tabular}

v. Marginal fluctuation in power demand in the area.

The estimated value of the fitness of all the transformers in their virtual substation are added together to form the objective function value. This fitness evaluation is carried out on all the chromosomes to see which of them will have the highest objective function value. The chromosomes with low fitness values are replaced with newly generated ones, while the ones with high fitness value will undergo selection, crossover and mutation (evolutionary procedures) and move to the next generation (iteration) with the hope of producing better fitness.

d. Selection and reproduction: A set of old chromosomes are selected to reproduce a set of new chromosomes according to the probability which is proportional to their fitness. They are carried out to preserve better solution candidates. Less fit candidates are discarded and new ones are generated to replace them.

e. Crossover: This is performed on two chromosomes at periods that are selected from the population. Each of the two strings is splinted into two and the head of the first is joined to the tail of the second, while the head of the second is joined to the tail of the first. The conceptual diagram of the process of a Crossover of Parents 1 and 2 chromosomes is shown in Figure 2.

f. Mutation: This involves selecting a chromosome and changing one of its bits from 0 to 1 or vice versa as shown in Figure 3.

The optimization procedure requires an objective function and the encoding techniques for the parameters of each transformer in each of the substations, which are used to estimate its fitness. After the substation records and control parameters have been entered, the methodology employed is as follows:

a. The solution begins with the random generation of initial population of chromosomes,

b. For each chromosome, evaluate the objective function and the fitness value. The objective function is determined according to the summation of the capacity utilization of all the transformers in the network,

c. If chromosome population converge or the specified number of iterations has been carried out (optimum solution likely reached), then the chromosome with the highest fitness value is obtained as the optimal solution,

d. Select the new population using the principle of selection and reproduction described above (evolutionary principle),

e. Apply crossover and mutation on the new population and go to Step b.

The block diagram of the procedures described above is shown in Figure 4. At the end of the optimization procedure, the chromosome with the highest fitness value is taken as the optimal solution.

\section{IMPLEMENTATION OF THE PROPOSED ALGORITHM}

Prior to implementation, several choices were made concerning the parameters that serve as tools in controlling the GA procedure. Care was taken to ensuring that the set of choices is fit enough to produce optimal

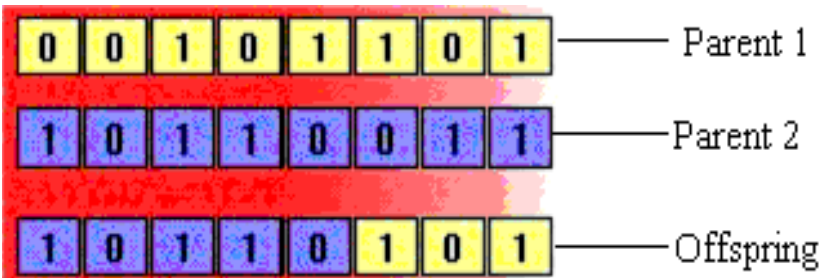

Figure 2. A visual diagram for crossover.

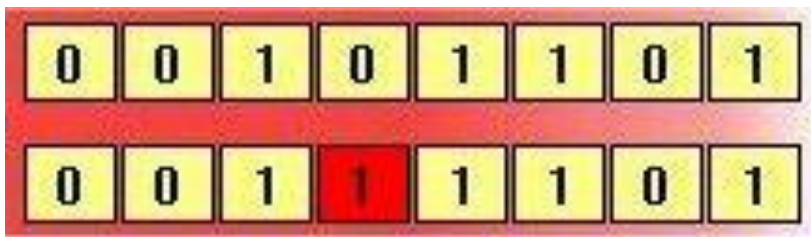

Figure 3. A visual diagram for mutation.

results. Before optimization, the position of transformers in electrical distribution system is processed, the required information, which comprise of the control parameters for the processing and substation in the District were determined. The input forms for creating the control parameters and the substation databases are shown in Figures 5 and 6 , respectively. Parameters such as population size, the number of substations/transformers in the system, crossover type (Single Point) in this case, mutation probability, number of years and iterations were appropriately selected.

Processing via GA begins with the reading of district and substations record from the database as shown in Figure 7. Read data are then converted into a set of strings where a substation is represented by a 3-digit string which the GA procedure can work upon. Therefore, the number of strings that form a chromosome will be three times the number of substation. The procedure is iterative and at the end of each iteration, genetic operators act on the chromosomes that allocate each transformer in the system (crossover and mutation). At the end, the fitness of each chromosome is evaluated using the objective function. The one that has the highest fitness is temporarily stored for future comparison. Those with the least fitness are discarded and new chromosomes are generated to continue the processes until the number of required iteration is reached. At the end of the whole process, the best-fit chromosomes 


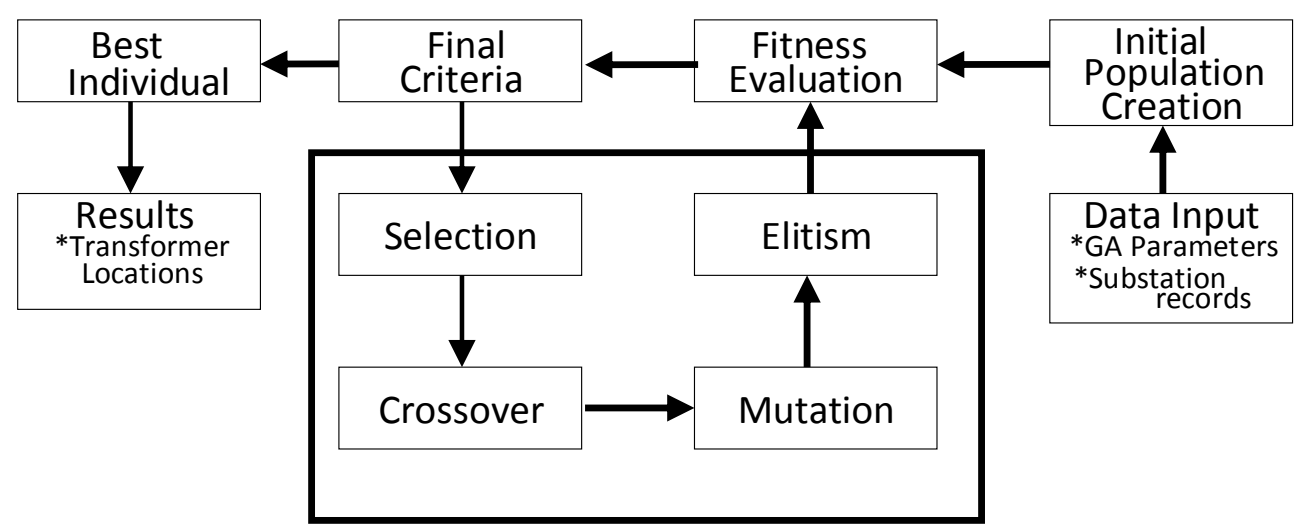

Figure 4. Optimization procedural block diagram for optimal transformer allocation in electrical distribution networks.

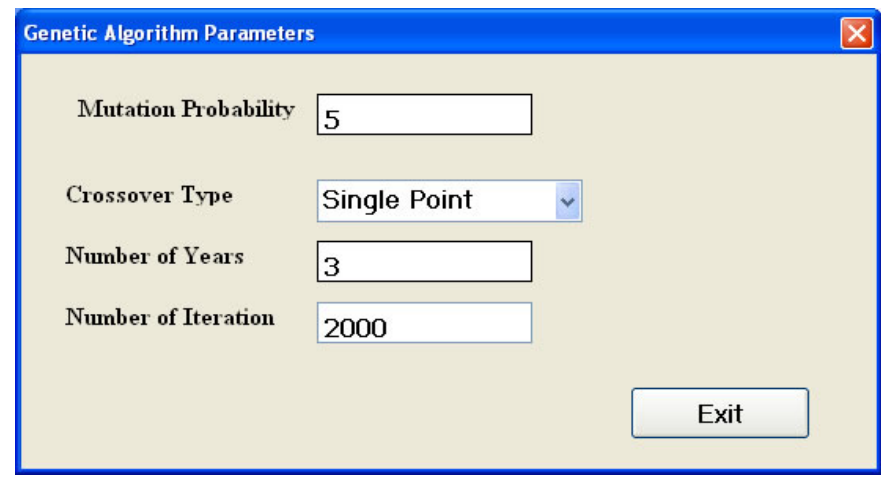

Figure 5. Input form for GA control parameters.

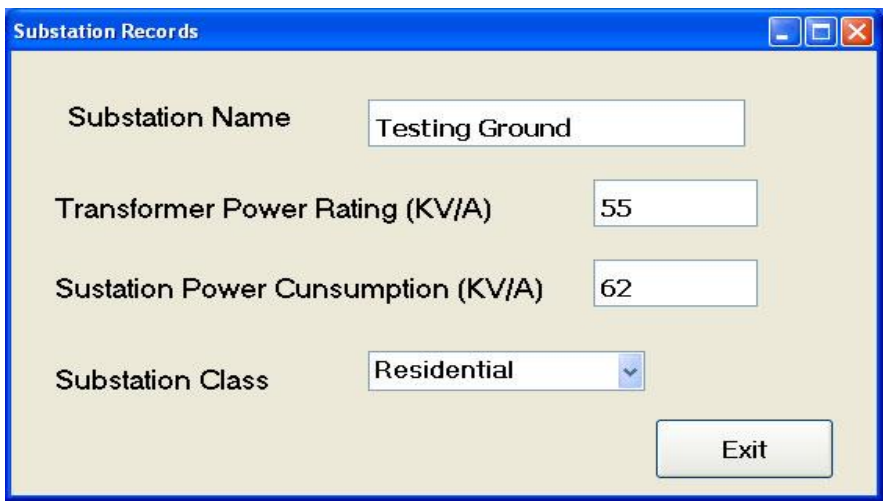

Figure 6. Entering form for substations data.

stored for each of the iterations are compared and the one that evaluates to best fitness is chosen for the allocation of transformers into the appropriate substations. For optimal performance, all underused or overused transformers are relocated to appropriate and rightful substations.

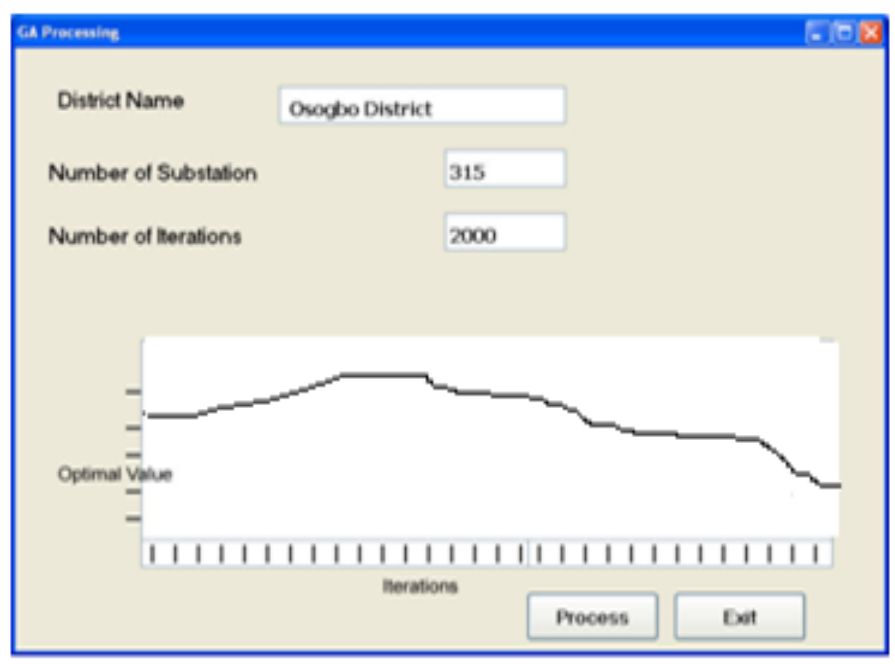

Figure 7. Processing via GA.

A case study of Osogbo electricity distribution district (OEDD) of Power Holding Company of Nigeria (PHCN) was carried out. The schematic diagram of the district is shown in Appendix 1. OEDD is one of the oldest districts of the electricity company in Nigeria and several other districts had been carved out from it. Presently, the district has a customer population of about 571,056 spreading across its 135 substations in five geographical units or undertakings that include Osogbo, Okefia, Ayetoro, Ikirun and Ila. Electricity is distributed to the end users in the district from a $33 \mathrm{KVA}$ power source (Ojo, 2012). The matrix of the current and optimized transformer allocations in the district is presented in Table 2. Optimization of transformer allocations via GA indicates a fair but un-optimized allocation of transformers in the network with significant numbers of sub-utilized (SU) as well as over-utilized (OU) transformers. 
Table 2. Current and optimized transformer allocation in Osogbo District, Nigeria.

\begin{tabular}{|c|c|c|c|c|c|}
\hline \multirow{2}{*}{ Sub Id } & \multirow{2}{*}{ Name of substation } & \multicolumn{2}{|c|}{$\begin{array}{c}\text { Current } \\
\text { transformer allocation }\end{array}$} & \multicolumn{2}{|c|}{$\begin{array}{c}\text { Optimized } \\
\text { transformer allocation }\end{array}$} \\
\hline & & $\begin{array}{c}\text { Capacity Distr. } \\
\text { T/F (KVA) }\end{array}$ & $\begin{array}{l}\text { Loading } \\
\text { (KVA) }\end{array}$ & $\begin{array}{l}\text { Capacity Distr. } \\
\text { T/F (KVA) }\end{array}$ & $\begin{array}{l}\text { From } \\
\text { Sub Id }\end{array}$ \\
\hline 1 & Nulge & 500 & 280 & 500 & 113 \\
\hline 2 & Osogbo Local Govt. & 300 & 399 & 200 & 35 \\
\hline 3 & Idi Baba & 300 & 105 & 200 & 38 \\
\hline 4 & Oke ljetu & 300 & 330 & 200 & 77 \\
\hline 5 & Federal Housing & 300 & 120 & 200 & 80 \\
\hline 6 & Owode Village & 200 & 198 & 100 & 47 \\
\hline 7 & Egbeda & 200 & 136 & 200 & 9 \\
\hline 8 & Cooker III & 200 & 110 & 300 & 3 \\
\hline 9 & Cooker II & 200 & 100 & 200 & 10 \\
\hline 10 & Cooker I & 200 & 106 & 200 & 11 \\
\hline 11 & Oredunmi & 200 & 106 & 100 & 134 \\
\hline 12 & Gaa Fullani & 200 & 156 & 200 & 8 \\
\hline 13 & Industrial Park & 1000 & 820 & 1000 & 13 \\
\hline 14 & LAUTECH (Asubiaro) & 500 & 440 & 300 & 62 \\
\hline 15 & OSBC & 500 & 475 & 500 & 53 \\
\hline 16 & Uniosun & 500 & 280 & 300 & 61 \\
\hline 17 & UNESCO & 500 & 365 & 300 & 4 \\
\hline 18 & Nursing School Hostel & 300 & 204 & 300 & 64 \\
\hline 19 & Crown Hotel & 200 & 240 & 300 & 5 \\
\hline 20 & Fountain University & 200 & 196 & 200 & 78 \\
\hline 21 & Asubiaro State Hospital & 200 & 144 & 100 & 87 \\
\hline 22 & Mini Water Works & 200 & 132 & 300 & 122 \\
\hline 23 & Auxilliary (Odi Olowo) & 100 & 92 & 100 & 133 \\
\hline 24 & MTN Idi Baba & 50 & 37.5 & 50 & 24 \\
\hline 25 & MTN (Ife Oluwa) & 50 & 38.5 & 50 & 25 \\
\hline 26 & Ebenezer & 500 & 385 & 500 & 115 \\
\hline 27 & Station Rd. & 500 & 365 & 500 & 49 \\
\hline 28 & Terminus & 500 & 440 & 300 & 58 \\
\hline 29 & Old garage & 500 & 380 & 500 & 17 \\
\hline 30 & Igbonna & 500 & 535 & 500 & 27 \\
\hline 31 & Fagbewesa & 300 & 243 & 300 & 65 \\
\hline 32 & Adenle & 300 & 219 & 315 & 129 \\
\hline 33 & Orisunbare Market & 500 & 530 & 500 & 72 \\
\hline 34 & LAUTECH Teaching Hosp & 500 & 610 & 500 & 29 \\
\hline 35 & TIB/Spring Bank & 200 & 174 & 300 & 125 \\
\hline 36 & UBA & 300 & 195 & 300 & 124 \\
\hline 37 & Wema Bank & 300 & 291 & 200 & 82 \\
\hline 38 & Fist Bank PLC & 200 & 176 & 200 & 131 \\
\hline 39 & OSICOL Water & 200 & 148 & 200 & 22 \\
\hline 40 & Computer & 200 & 200 & 200 & 81 \\
\hline 41 & STB/UBA & 100 & 61 & 100 & 41 \\
\hline 42 & Union Bank & 100 & 72 & 100 & 68 \\
\hline 43 & District Office & 100 & 73 & 100 & 45 \\
\hline 44 & O’Net Otakiti & 100 & 94 & 100 & 100 \\
\hline 45 & SKYE Bank Fagbewesa & 100 & 65 & 100 & 94 \\
\hline 46 & Ademola Rasaq & 100 & 89 & 300 & 130 \\
\hline 47 & Intercontinenter Bank & 100 & 99 & 100 & 42 \\
\hline 48 & MTN Opp.Post Office & 50 & 56.5 & 50 & 135 \\
\hline
\end{tabular}


Table 2. Contd.

\begin{tabular}{|c|c|c|c|c|c|}
\hline 49 & Coca-Cola & 500 & 335 & 500 & 69 \\
\hline 50 & Baruwa & 500 & 540 & 500 & 26 \\
\hline 51 & Eleyele Estate & 500 & 385 & 500 & 51 \\
\hline 52 & Ogo-Oluwa & 500 & 570 & 500 & 116 \\
\hline 53 & Omigade & 500 & 320 & 500 & 117 \\
\hline 54 & Odetoyinbo & 500 & 645 & 500 & 55 \\
\hline 55 & Sazo & 500 & 395 & 500 & 120 \\
\hline 56 & Ibuamo Abija Area & 500 & 190 & 300 & 123 \\
\hline 57 & Olosan II Ogo-Oluwa Area & 500 & 295 & 300 & 2 \\
\hline 58 & Folakunle & 300 & 354 & 300 & 66 \\
\hline 59 & Heritage & 300 & 150 & 500 & 56 \\
\hline 60 & Olosan & 300 & 225 & 300 & 127 \\
\hline 61 & Zarah & 300 & 321 & 300 & 36 \\
\hline 62 & Ataoja Est. & 300 & 318 & 200 & 20 \\
\hline 63 & Oladipo & 300 & 423 & 200 & 6 \\
\hline 64 & Ibukunoluwa & 300 & 177 & 200 & 40 \\
\hline 65 & Palm Crest Hotel & 300 & 177 & 300 & 18 \\
\hline 66 & Olasamson & 300 & 186 & 200 & 83 \\
\hline 67 & Kamar Dairo & 200 & 80 & 200 & 7 \\
\hline 68 & Raji Kolade & 100 & 64 & 100 & 100 \\
\hline 69 & Gov's Office I & 500 & 380 & 500 & 114 \\
\hline 70 & Gov's Office II & 500 & 270 & 500 & 118 \\
\hline 71 & Abere I & 500 & 485 & 500 & 74 \\
\hline 72 & CBN I Opposite NECO & 500 & 375 & 500 & 111 \\
\hline 73 & CBN II Abere & 500 & 440 & 300 & 63 \\
\hline 74 & Amorite & 500 & 410 & 300 & 32 \\
\hline 75 & House of Assembly I & 300 & 237 & 500 & 14 \\
\hline 74 & House of Assembly II & 300 & 144 & 500 & 121 \\
\hline 75 & Fed. High Court & 300 & 225 & 300 & 128 \\
\hline 76 & Custom & 300 & 291 & 300 & 60 \\
\hline 77 & Olaniyi Aina Petrol & 200 & 176 & 200 & 86 \\
\hline 78 & First Bank & 200 & 120 & 300 & 126 \\
\hline 79 & Access Bank & 200 & 142 & 200 & 79 \\
\hline 80 & Health Trust Fund & 200 & 176 & 200 & 21 \\
\hline 81 & INEC & 200 & 134 & 300 & 74 \\
\hline 82 & NTA Osogbo & 200 & 184 & 200 & 39 \\
\hline 83 & Fidelity Bank & 200 & 210 & 300 & 59 \\
\hline 84 & Tantalizer & 200 & 154 & 200 & 84 \\
\hline 85 & Federal Pay Office & 200 & 166 & 200 & 12 \\
\hline 86 & Bank PHB & 200 & 138 & 300 & 129 \\
\hline 87 & Oceanic Bank & 100 & 120 & 100 & 134 \\
\hline 88 & Zenith Bank & 100 & 80 & 100 & 43 \\
\hline 89 & Ayinke Tower & 100 & 86 & 100 & 132 \\
\hline 90 & GTB & 100 & 79 & 100 & 102 \\
\hline 91 & Diamond Bank & 100 & 75 & 100 & 91 \\
\hline 92 & FCMB & 100 & 89 & 100 & 90 \\
\hline 93 & MTEL Ogo-Oluwa & 100 & 94 & 100 & 99 \\
\hline 94 & Fed. Inland Revenue & 100 & 69 & 200 & 67 \\
\hline 95 & FRSC & 100 & 85 & 100 & 88 \\
\hline 96 & Living Spring Hotel & 100 & 97 & 100 & 103 \\
\hline 97 & MTN Oke Pupa & 100 & 95 & 100 & 101 \\
\hline 98 & AIG Office & 100 & 93 & 100 & 108 \\
\hline
\end{tabular}


Table 2. Contd.

\begin{tabular}{|c|c|c|c|c|c|}
\hline 99 & Celtel, Owode Abere & 100 & 79 & 200 & 133 \\
\hline & Celtel, Gbongan /Ibadan & & & & \\
\hline 100 & $\mathrm{Rd}$ & 100 & 68 & 100 & 89 \\
\hline 101 & Abere Streetlighting & 100 & 83 & 100 & 104 \\
\hline 102 & Afri Bank & 100 & 74 & 100 & 46 \\
\hline 103 & Street Lighting & 100 & 82 & 100 & 92 \\
\hline 104 & Heritage Hotel & 100 & 86 & 100 & 23 \\
\hline 105 & Streetlighting & 100 & 96 & 100 & 98 \\
\hline 106 & Union Bank Gb/lb Road & 100 & 94 & 100 & 44 \\
\hline 107 & Streetlighting & 100 & 95 & 100 & 93 \\
\hline 108 & Sterling Bank & 100 & 84 & 100 & 106 \\
\hline 109 & SSS Office & 50 & 48 & 50 & 109 \\
\hline 110 & Zain Opp. Access Bank & 50 & 53.5 & 50 & 110 \\
\hline 111 & Jaleyemi & 500 & 415 & 500 & 28 \\
\hline 112 & Matanmi & 500 & 605 & 500 & 73 \\
\hline 113 & Exchange & 500 & 300 & 500 & 15 \\
\hline 114 & Oja-Oba & 500 & 400 & 500 & 71 \\
\hline 115 & Kajola & 500 & 330 & 500 & 33 \\
\hline 116 & Oke Abesu & 500 & 385 & 500 & 30 \\
\hline 117 & Oke Baale & 500 & 385 & 500 & 50 \\
\hline 118 & Custain & 500 & 405 & 500 & 52 \\
\hline 119 & Fadilulahi & 500 & 230 & 500 & 112 \\
\hline 120 & ST Charles & 500 & 395 & 500 & 34 \\
\hline 121 & Fadilulahi II & 500 & 215 & 500 & 54 \\
\hline 122 & Osogbo Local Govt & 300 & 120 & 300 & 75 \\
\hline 123 & Jimoh Buraimoh & 300 & 396 & 500 & 119 \\
\hline 124 & BetterLife & 300 & 183 & 300 & 75 \\
\hline 125 & Asubiaro I & 300 & 123 & 200 & 19 \\
\hline 126 & Asubiaro II & 300 & 138 & 300 & 131 \\
\hline 127 & Onireke & 300 & 192 & 300 & 31 \\
\hline 128 & Ifelodun & 300 & 222 & 500 & 70 \\
\hline 129 & Isale Aro & 300 & 159 & 500 & 1 \\
\hline 130 & Ikolaba & 300 & 69 & 500 & 57 \\
\hline 131 & Iso Ewe & 300 & 240 & 500 & 16 \\
\hline 132 & Ita-Olokan & 300 & 288 & 300 & 76 \\
\hline 132 & Bishop's Court(Oke Ayepe) & 300 & 285 & 200 & 85 \\
\hline 133 & Etisalat & 300 & 285 & 300 & 132 \\
\hline 133 & Iso Ata(Back of Palace) & 200 & 84 & 100 & 97 \\
\hline 129 & IDC II & 315 & 179.55 & 300 & 133 \\
\hline 130 & IDC I & 300 & 165 & 300 & 132 \\
\hline 131 & Palace & 200 & 128 & 100 & 107 \\
\hline 132 & Street Lighting Jaleyemi & 100 & 73 & 300 & 130 \\
\hline 133 & Sttreet Lighting, Ita-Olokan & 100 & 60 & 300 & 37 \\
\hline 134 & Tajudeen Oladipupo & 100 & 108 & 100 & 105 \\
\hline 134 & MTN Oke Ayepe & 100 & 72 & 100 & 96 \\
\hline 135 & Yetty Guest House & 50 & 44 & 50 & 48 \\
\hline
\end{tabular}

Visual inspection of the figures presented in Table 2 revealed that practical implementation of the algorithm will require several exchanges of transformers to where they best fit in the distribution network. For instance, transformers at substations with identifier 113, 35, 38, 77 and 80 could have been located at Nulge, Osogbo Local 
government, Ido Baba, Oke ljetu and Federal Housing, respectively. It is also shown that some transformers are to be disposed for new ones, for smooth and reliable distribution of electricity. Future research focuses on improving the algorithm to attain fully optimized transformer allocations in an electricity distribution network. This is expected to be achieved via the inclusion of some other relevant decision variables like customers' social class (private, commercial government) and environmental factors (temperature, humidity) in the objective function.

\section{Conclusions}

GA optimization technique has been proposed for resolving inadequacies inherent with the conventional or manual allocation of transformers in electrical distribution networks. The optimization procedure adequately allocated transformers to where they are best fit for energy transmission over reasonable lifespan in an electrical distribution. The system has an advantage over the manual system because it can be executed repeatedly and very helpful in the determination of how existing electricity distribution network could accommodate expansion.

\section{REFERENCES}

Adam M (2004). GAs and Evolutionary Computation. Talk Origins Archives.

Al-Abdulwahab A (2007). "Radial Electrical Distribution Systems Automation Using GA", J. King Abdulaziz University Eng. Sci. 18(2).

Bhasker K, Vijay M, Albert W, Debmalya B (2013). Mathematical Modeling of Optimizing Power Stream Measurement Using GA, Am. J. Eng. Res. (AJER), 2(10):71-79.

Bogdan T, Mircea C, Andreas S, Sudria-Andreu A, Roberto VR (2013). Pareto Optimal Reconfiguration of Power Distribution Systems Using a GA Based on NSGA-II, Int. J. Energies 6:1439-1455; doi:10.3390/en6031439

BOPL (2012) Broadband Over Power Lines. A White Paper (www.state.nj.us/rpd/BLPw Hitepaper.pdf), Accessed 23/07/2013.

Carpinelli G, Mottola F, Proto D, Russo A (2010). Optimal Allocation of Dispersed Generators, Capacitors and Distributed Energy Storage Systems in Distribution Networks, Modern Electric Power Systems 2010, Wroclaw, Poland.

Chia-Hung L, Meei-Song K, Hui-Jen C, Chin-Ying H (2007). Phase Balancing of Distribution Systems Using a Heuristic Search Approach (www.jicee.org/inc/download.asp? PR_ldx=148), Accessed $12 / 10 / 2013$

Culverco (2005). Electricity Generation and Distribution; Science and Safety of Electricity http://www.culverco.com/sse/power.

Ellithy K (2007). Optimal shunt capacitors allocation in distribution networks using GA. Int. J. Innov. Energy Syst. Power 3(1).

Ellithy K, Al-Hinai AS, Moosa AH (2008). "Optimal Shunt Capacitors Allocation In Distribution Networks Using Genetic Algorithm- Practical Case Study". Int. J. Innovations Energy Syst. Power, IJIESP. 3(1).

Holland J (1975). GA (http://www.cc.gatech.edu/ turk/ bio_sim/articles/genetic_algorithm.pdf), Accessed 27/02/20143
Kumara S, David G, Graham K (2009). GAs (.http://citeseerx.ist.psu.edu/ viewdoc/download?doi=10.1.1.61.6575\&rep=rep1\&type=pdf), Accessed 27/02/2014

Lijun C, István E, Georgios S, Yicheng L (2008). Optimal choice and allocation of facts devices in deregulated electricity market using GAs (https://www.uni-due.de/ean/downloads/ papers/irep-erlich08.04.pdf), Accessed 05/11/2013.

Luger GF (2002). Introduction to GA, working principle: Electrical Power Distribution Engineering; North Maharashtra University, Jalgaon.

Mahela OMP, Ola SR (2013). Optimal capacitor placement for loss reduction in electric transmission system using GA, Int. J. Electr. Electron. Eng. Res. (IJEEER) 3(2):59-68.

Milbrandt A, Mann M (2009). Hydrogen resource assessment hydrogen potential from coal, natural as, nuclear, and hydro power, technical report of united states national renewable energy LaboratoryNREL/TP-560-42773 (http://www.nrel.gov/docs/fy09osti/42773.pdf).

Mitchell M (1999). An Introduction to GAs, Bradford Book The MIT Press, Cambridge, Massachusetts. London, England.

Ojo AM (2012). Development of genetic algorithm for optimal transformer allocation in electrical distribution networks, M. Tech. Thesis, Department of Computer Science, Federal University of Technology, Akure, Nigeria.

Rahmat-Allah H, Mohammad A (2007). Optimal capacitor placement in actual configuration and operational conditions of distribution systems using RCGA. J. Electr. Eng. 58(4):189-199.

Shahram J (2006). Software development for optimum allocation of power system elements based on GA, Proceedings of the 6th WSEAS International Conference on Power Systems, Lisbon, Portugal, September 22-24, 2006.

Sreejaya P, lyer RS (2012). Reactive Power Control by GA in AC-DC Systems, Lecture Notes in Information Technology, International Conf. Future Electr. Power Energy Syst. Vol. 9.

Takahashi S, Yasuhiro H, Masaki T, Eiji K (2012). Method of optimal allocation of $\mathrm{svr}$ in distribution feeders with renewable energy sources. J. Int. Counc. Electr. Eng. 2(2):159-165.

Tiago A, Anselmo R, Maria da Guia da S (2011). Switches Allocation in Distribution Network Using Particle Swarm Optimization Based on Fuzzy Expert System, Proceedings of 7th Power Systems Computation Conference Stockholm Sweden.

U.S. Department of Labor (2009). Occupational Safety and Health Administration: Electricity Generation, Transmission and Distribution. www.osha.gov.

Li Y (2009). Using Niche GA to Find Fuzzy Rules, Proceedings of the 2009 International Symposium on Web Information Systems and Applications (WISA'09), Nanchang, P. R. China, pp. 64-67. 
Appendix 1. Conceptual diagram of Osogbo, Nigeria District 11KVA.

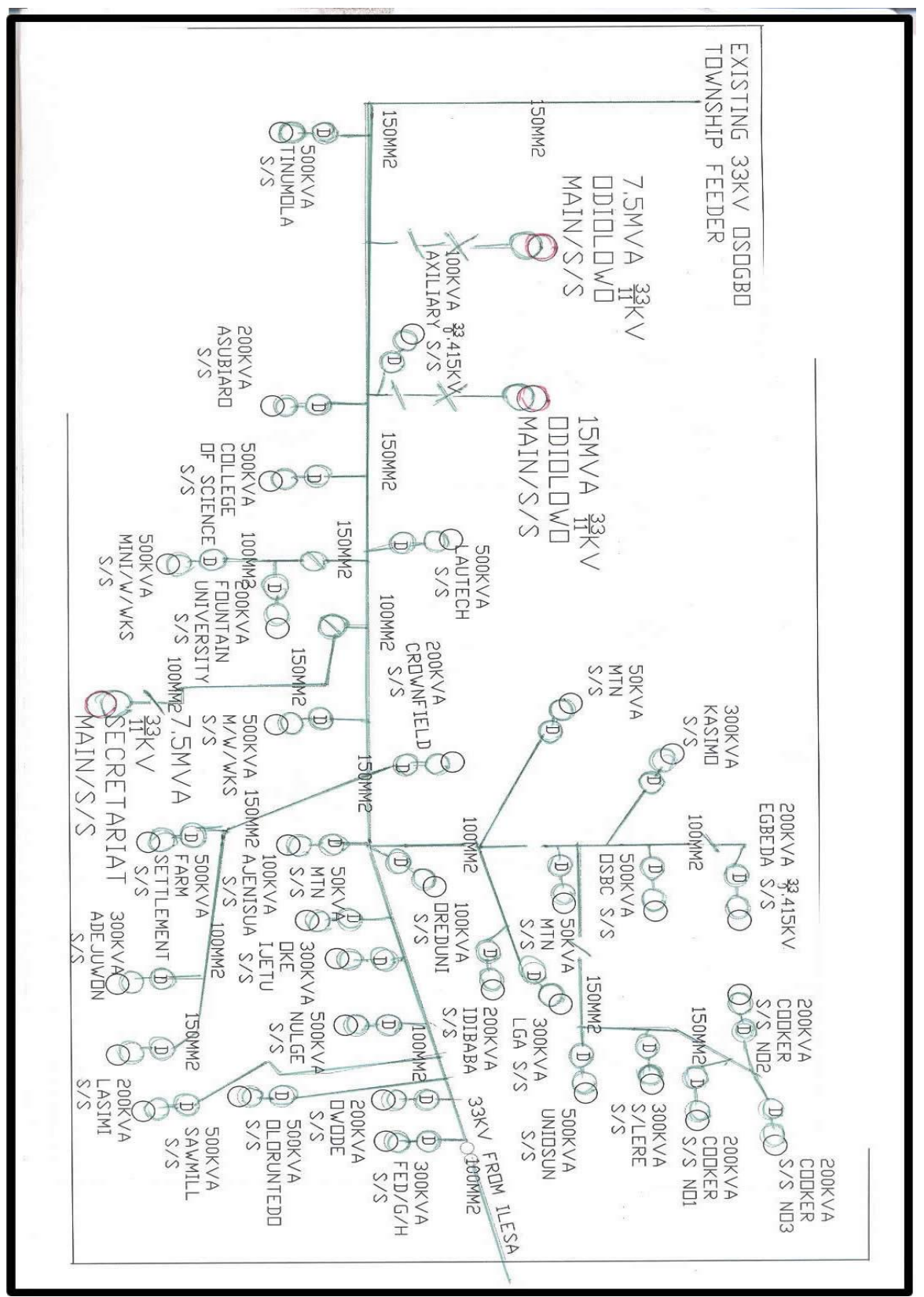

